hypothesis is, then, the true one, and the inner surface is electrified positively.

The explanation of both the direct and inverse rotation follows naturally from these facts and those communicated in my former note. For since the inner surface, when exposed to luminous or calorific radiations, is electrified positively, the direct rotation is a necessary consequence of the attractions and repulsions which this positive electricity exerts upon the free electricity of the vanes. This rotation continues when the radiometer is surrounded by light, because a perfectly homogeneous layer of electricity upon the inner surface is almost impossible.

The inverse rotation occurs in two circumstances-

I. When the instrument, having been exposed to radiation which produces a direct rotation is allowed to cool slowly.

2. When the radiometer at the ordinary temperature is cooled suddenly, for instance, by moistening it with ether.

In the first case, the electricity which the globe acquires when exposed to radiation disappearing very slowly, as experiments show, an inversion of the movement can be produced by an inversion in the signs of the electricity of the vanes. In fact, in accordance with the principle of reciprocity, the emission of the radiations gives rise in the vanes to a development of electricity equivalent and contrary to that which absorption has produced there. By this development of electricity the vanes would return to their neutral state if the electricity produced by absorption had not passed in part from the vanes into the rarefied gas of the globe. Now this passage took place with a greater energy as the rotary movement of the vanes had renewed more frequently the mass of air in contact with them. Hence the electric effect of the emission will be to change the signs and to dininish the charge of free electricity of the vanes.

In the second case, where the cooling is produced by moistening the exterior, the globe remains in its neutral state. For, as I have above remarked, during the whole time of the inverse rotation, the cooled surface of the globe gives no signs of electricity. It appears that the cooling itself is not capable of producing electricity, but that the passage of a radiation through the surface is absolutely required. In these conditions the vanes become charged with negative electricity upon the dark, and positive upon the bright side, by reason of the emission, at the same time that the radiations given forth by the vanes and $a b$. sorbed by the inner surface of the glass globe electrify the latter positively.

Thus the electric theory of the radiometer explains quite well the principal phenomena which have been observed up to the present time. I hope to make, hereafter, a study of all the particular movements which different observers have noted in the accounts of their experiments. I will only say now that the most remarkable of them, viz., the rotation of the radiometer globe, when an obstacle is put to the rotation of the vanes, as discovered by Schuster, is in entire conformity with the above theory, while it constitutes a very serious objection to the hypothesis of mechanical impulsion by radiation.

Joseph DeLsaulX, S.J.

II, rue des Récollets, Louvain

\section{A Rudimentary Tail}

A DAY or two ago a curious and interesting abnormality came under my notice, which, I think, deserves mention. I was examining the back of a girl, aged about eight, when $I$ saw over the lower part of the sacrum, in the middle line of the back, a small hole, that, on the first glance, seemed like the opening of an old sinus. I was told, however that it had been present since birth, and I then looked at it more carefully. It had a direction downwards and somewhat forwards, and consisted of a reflection of the skin entering a more or less circular depression, about $\frac{1}{3}$ inch in diameter, and about $\frac{1}{4}$ inch deep. Not quite $\frac{1}{4}$ inch below its lower border could be felt the pointed extremity of the coccyx, which, instead of having its usual form, curved backwards and rather upwards. On stretching the skin downwards, that portion of it entering the depression or hole was raised, coming out like the top part of the finger of a glove which had been pressed down into the lower part, and a small prominence, about the height of the diameter of a pea, stood up from the surface; and this little sheath was found to cover and exactly fit the sharp end of the coccyx. The resemblance this bore to a rudimentary tail was sufficientiy striking.

Jersey

ANDREW DUNLOP
The Aolian Fornation on the Lancashire Coast

IN the absence of large works on the subject, has your recent Waterloo correspondent seen the Survey memoir of the district around Southport in which the phenomena of wind dififtage are treated in a brief yet quantitative manner? The efficient way in which pebbles and shells-as of Mactra stultorum (with which the shore is so plentifully covered)-especially when the convex side of a valve is presented vertically towards the direction of the storm winds, protect a small area to leewaró, forming a miniature crag-and-tail arrangement, would seem to suggest that a solid screen offering an unbroken surface to the action of the wind, and at some distance from the region threatened, would be far more useful than the present expedients of growing marram grass, \&c., to consolidate the dunes, or of planting lines of bare stakes. Practical men would easily devise a cheaply constructed barrier of old ship-timber faced with ling or other accessible material, or perhaps use the sand-hills themselves when armoured with tabular blocks of stone made on the spot by some such pro. cess as employed in the construction of the sea-walls of the Suez Canal. Land sold for building plots on exposed points ought surely to have some adequate defence against the devouring sand.

Manchester, Sept, I5

WILLIAM GEE

\section{OUR ASTRONOMICAL COLUMN}

THE TOTal SOLAR ECLIPSE OF 1885 , SEPT. 8-9.The following elements, though approximate only, will suffice to give a pretty fair indication of the circumstances under which the totality of this eclipse will take place :-

Conjunction in R.A., r885, Sept. 8, at 9h. $18 \mathrm{~m} .58 \mathrm{~s}$. G.M.T.

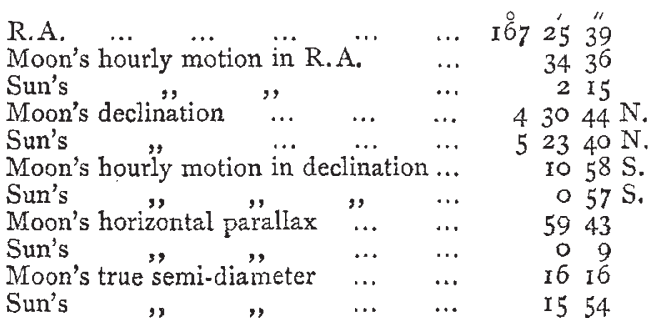

Hence the central and total eclipse begins upon the earth in long. $156^{\circ} 54^{\prime} \mathrm{E}$., lat. $40^{\circ} 54^{\prime} \mathrm{S}$., and ends in long. $75^{\circ} 33^{\prime} \mathrm{W}$., Iat. $74^{\circ} 38^{\prime} \mathrm{S}$., and the sun is centrally eclipsed at apparent noon in long. $138^{\circ} 39^{\prime}$ W., lat. $57^{\circ} 40^{\prime} \mathrm{S}$.

The following are also points upon the central line :-

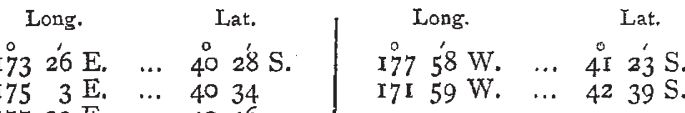

... 4034

The semi-diameter of the shadow in these longitudes is about $55^{\prime}$. It would therefore appear that observations are not likely to be made to any useful purpose, except in the southern part of the northern island of New Zealand, and here the sun will have no great elevation above the horizon. If we calculate from the above elements directly for Wellington, assuming the longitude of this place IIh. 39m. 20s: E., and its latitude $4 \mathrm{I}^{\circ} \mathrm{I} 7^{\prime}$, we find-

h. m. s.

Partial eclipse begins Sept. 9 at 6 r 8 o A.M. ) Mean times

Total ", begins ", 74222 " $\quad \begin{array}{r}\text { Mean time at } \\ \text { at }\end{array}$

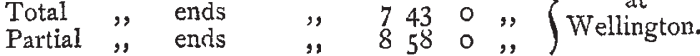

And therefore the duration of totality 38 seconds oniy, with the sun at an altitude of $55^{\circ}$.

Calculating similarly for one of the points upon the central line, some fifty miles north of Wellington, or long. $175^{\circ} 3^{\prime} \mathrm{E}$, lat. $40^{\circ} 34^{\prime}$, the totality is found to commence at $7 \mathrm{~h}$. $4 \mathrm{Im}$. 3 Is. A.M., local mean time, and to con. tinue $1 \mathrm{~m}$. 54s., with the sun at an altitude of $16^{\circ}$.

At Wellington the sun rises at $6 \mathrm{~h} .2 \mathrm{Im}$. 